\title{
Asymmetric organocatalytic synthesis of cyclopentane $y$-nitroketones
}

Article

Accepted Version

Al-Ani, W., Shankland, K. and Cobb, A. J. A. (2016)

Asymmetric organocatalytic synthesis of cyclopentane $\mathrm{Y}^{-}$ nitroketones. Synlett, 27 (1). pp. 17-20. ISSN 0936-5214 doi: https://doi.org/10.1055/s-0035-1560504 Available at https://centaur.reading.ac.uk/44844/

It is advisable to refer to the publisher's version if you intend to cite from the work. See Guidance on citing.

To link to this article DOI: http://dx.doi.org/10.1055/s-0035-1560504

Publisher: Thieme

All outputs in CentAUR are protected by Intellectual Property Rights law, including copyright law. Copyright and IPR is retained by the creators or other copyright holders. Terms and conditions for use of this material are defined in the End User Agreement.

\section{www.reading.ac.uk/centaur}

\section{CentAUR}

Central Archive at the University of Reading

Reading's research outputs online 


\section{Asymmetric organocatalytic synthesis of cyclopentane $\gamma$-nitroketones}

\author{
Widad Al-Ani \\ Kenneth Shankland \\ Alexander J. A. Cobb* \\ School of Chemistry, Food and Pharmacy, University of \\ Reading, Whiteknights, Reading, Berks RG6 6AD \\ * indicates the main/corresponding author. \\ a.j.a.cobb@reading.ac.uk
}

Dedicated to Professor Steven V. Ley CBE FRS on the occasion of his $70^{\text {th }}$ birthday

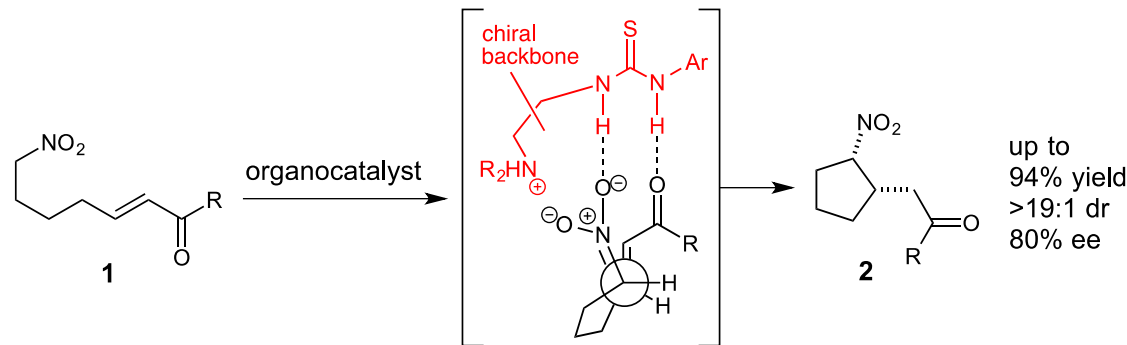

\section{Received:
Accepted:
Published online: \\ DOI:}

Abstract This paper described the use of bifunctional thiourea catalysts in the intramolecular reaction of a nitronate with conjugated ketones to generate the corresponding $y$-nitroketones. In contrast to our previous studies in this area, we obtained the cis-functionalised systems as the major diastereoisomer in good yield and reasonable selectivities.

Key words organocatalysis, nitronate, cyclization, Michael addition, $\gamma$ nitroketone

The formation of new carbon-carbon bonds in a stereoselective and efficient manner is central to organic chemistry. In particular, methods that have an ease of utility, and that are environmentally benign have rightly become a focus of these studies. As such, organocatalysis has become a rapidly growing field which has shown a broad spectrum of behavior and utility. ${ }^{1}$ Our interest in this area originated in our desire to construct novel amino acid precursors in a rapid and highly selective manner. As such, we have described the synthesis of a number of unnatural $\gamma$-amino acids, which have been constructed using hydrogen-bonding catalysis using either a nitro-group or a sulfone as the nucleophilic handle. ${ }^{2}$ However, attempts at constructing the corresponding five-membered systems have been met with much lower selectivities, despite the attempted use of alternate catalyst methods. ${ }^{3}$ In an attempt to improve upon this, we decided to change the nature of the electrophilic component from conjugated esters to conjugated ketones $\mathbf{1}$ (Figure 1A). Although this would not easily lead to amino acid precursors, we felt that the resulting adducts were interesting frameworks in their own right, and could be used in the construction of bicyclic pyrrolidine systems (Figure 1B). Examples of compounds that contain this functionality include the antihypertensive, ramipril and the DE ring system of the Solanum class of alkaloids (Figure 1B, highlighted in red). ${ }^{4}$

A

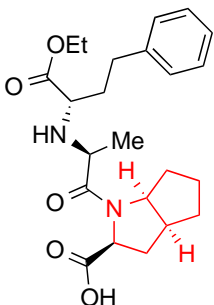

Ramipril

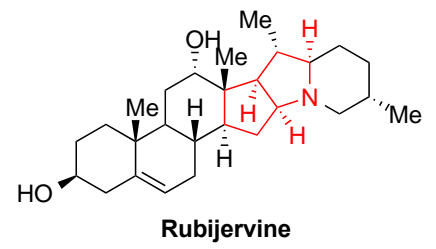

Rubijervine

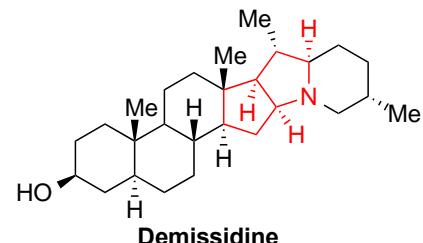

Figure 1(A) Concept : Synthesis of $\gamma$-nitroketone (B) Example occurances of the bicyclic pyrrolidine framework

Our starting point was the simple substrate $(E)$-10-nitrodec-5-en-4one 1a, which was made in two steps via standard formation of the $\beta$-ketophosphonate and subsequent Horner-Wadsworth-Emmons reaction according to literature procedure. ${ }^{5}$ With this test substrate in hand, we subjected it to a number of thiourea catalysts (Table 1, representative examples shown), ${ }^{6}$ using conditions we found to be favourable for a similar reaction in another study, ${ }^{2 a}$ and discovered that the cinchonine derived system I fared best in terms of enantioselectivity (Table 1, Entry 1). The related hydroquinine system II gave reduced enantioselectivities (Entry 2), and the $\mathrm{C}_{2}$ symmetric catalyst III, $^{7}$ lacking an internal Lewis base, gave only a stoichiometric amount of product at a reduced enantioselectivity (Entry 3). A subsequent screen of solvent and catalyst load confirmed that organocatalyst I, when used at $20 \mathrm{~mol} \%$ in 
acetonitrile was indeed the best option. Intriguingly, the diastereoselectivity of the process was hugely dependent upon solvent, and could even be moderately reversed in some cases
(Entries 7 and 8). Also of note, is the fact that a lower loading of organocatalyst leads to lower selectivities (Entries 1, 4 and 5).

Table 1. Catalyst and solvent screen for the asymmetric formation of $\gamma$-nitroketones

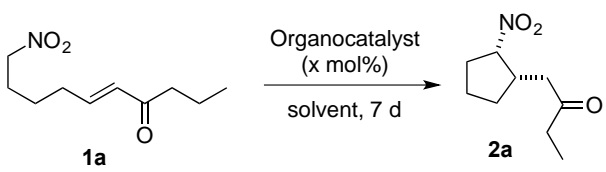

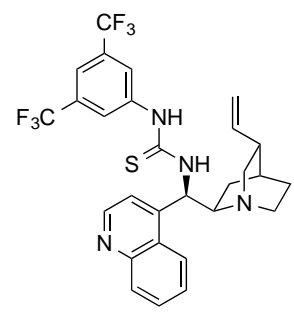

I

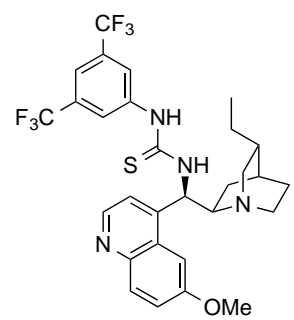

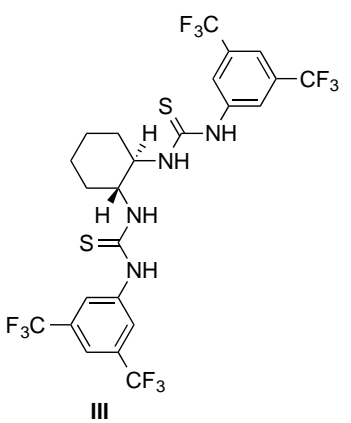

\begin{tabular}{|c|c|c|c|c|c|c|}
\hline Entry & Catalyst & Mol\% & Solvent & Yield, $\%^{a}$ & $\mathrm{Dr}^{b}$ & ee $\%$ (major) $^{c}$ \\
\hline 1 & $\mathbf{I}$ & 20 & $\mathrm{MeCN}$ & 60 & $>19: 1$ & 80 \\
\hline 2 & II & 20 & $\mathrm{MeCN}$ & 73 & $2: 1$ & 64 \\
\hline 3 & III & 20 & $\mathrm{MeCN}$ & 20 & $17: 1$ & 40 \\
\hline 4 & I & 10 & $\mathrm{MeCN}$ & 56 & $6: 1$ & 64 \\
\hline 5 & I & 5 & $\mathrm{MeCN}$ & 76 & $3: 1$ & 49 \\
\hline 6 & I & 20 & $\mathrm{CH}_{2} \mathrm{Cl}_{2}$ & 80 & $6: 1$ & 29 \\
\hline 7 & I & 20 & DCE & 77 & $1: 2$ & 43 \\
\hline 8 & I & 20 & $\mathrm{MeOH}$ & 83 & $1: 3$ & 25 \\
\hline 9 & I & 20 & THF & 60 & $11: 1$ & 51 \\
\hline 10 & I & 20 & MeOH:MeCN, 1:1 & 65 & $5: 1$ & 45 \\
\hline
\end{tabular}

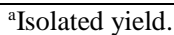

${ }^{\text {b}}$ Determined by $1 \mathrm{H}$ NMR spectroscopy.

'Determined by chiral-phase HPLC using a Chiralpak AD-H column and detection by UV at $280 \mathrm{~nm}$

We then examined the scope of the process using a variety of different conjugated ketones, and pleasingly found that each of them generated the corresponding cyclized compound in good yield and with reasonable enantiomeric excess (Table 2). The alkyl ketones (Entries 1-3) in particular performed well under our conditions with excellent diastereoselectivity and useful enantioelectivities, which were certainly an improvement upon the related conjugated ester systems using similar catalytic conditions. Indeed diastereoselectivity was generally good, except for the pivaloyl system 2 e (Entry 6), which also suffered from (relatively) reduced yield and enantioselectivity presumably due to the steric constraints within this system. We also succeeded in preparing an adduct containing three contiguous stereocentres - the yield in this case was much reduced, but nevertheless the enantioselectivity was very pleasing (Entry 9).

In order to ascertain the relative stereochemistry of the adducts, a single crystal of compound $\mathbf{2 d}$ was grown and a crystal structure obtained by X-ray diffraction using copper incident radiation. The crystal structure itself (CCDC deposition 1406015), in the centrosymmetric space group Pbca, is unremarkable but fascinatingly shows the relative configuration on the ring to be cis in nature (Figure 2). In many of the related systems that we have studied, we observe that under the reaction conditions, the cis system tends to equilibrate to the thermodynamically more favourable trans adduct. However in this case, such equilibration does not seem to occur to the same extent. This could well be to do with the reversibility of conjugate additions into conjugated esters vs the corresponding conjugated ketone systems in this study. The configuration of the other substrates was assigned by analogy.

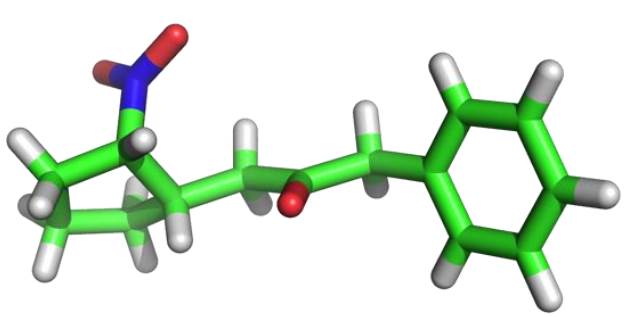

Figure 2 : The relative configuration of the adduct $2 \mathrm{~d}$, as determined by single-crystal X-ray crystallography. CCDC no: 1406015

http://www.ccdc.cam.ac.uk.

The rationale for the formation of the cis-adduct follows on from our conjucture $\mathrm{e}^{\mathrm{a}, \mathrm{b}}$ that in order to have reasonable reactivity, both the electrophilic ketone and the nucleophilic nitronate must be co-ordinated simultaneously. A third interaction between the protonated tertiary amine and the other nitronate 
anion cements the chiral environment, leading to the transfer of stereochemical information (Figure 3).

Table 2 : Substrate scope for the asymmetric formation of $\gamma$-nitroketones. ${ }^{8}$
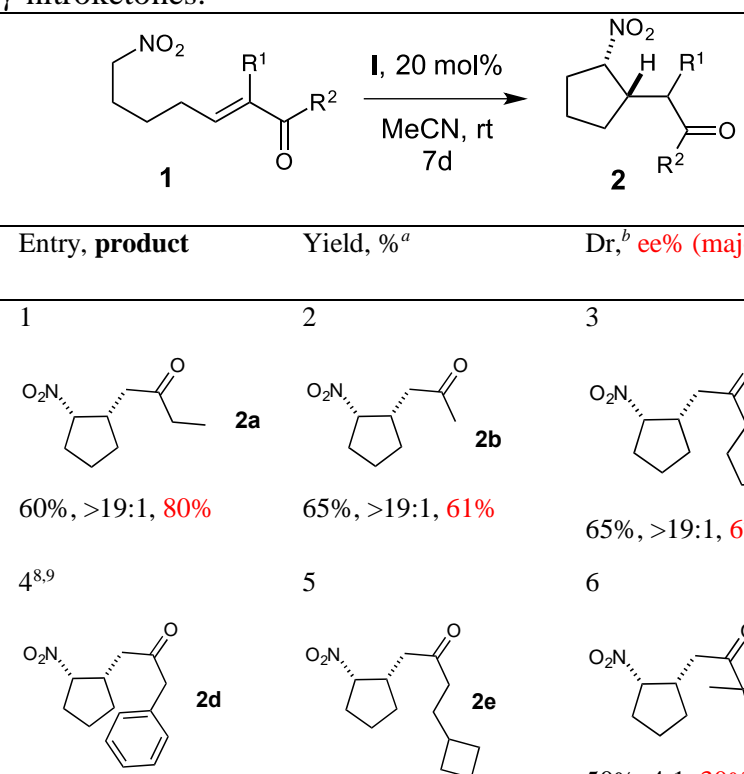

$94 \%,>19: 1,65 \%$

7

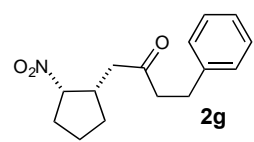

$86 \%, 9: 1,30 \%$

Yield, $\%^{a}$

$\mathrm{Dr}^{b}$ ee\% (major)

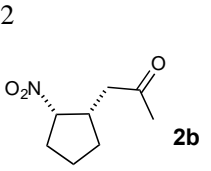

$65 \%,>19: 1,61 \%$

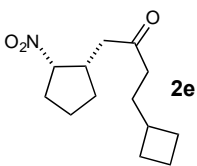

$80 \%, 3: 1,66 \%$

$80 \%, 15: 1,8 \%$

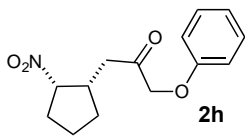

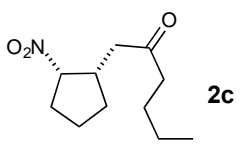

$65 \%,>19: 1,67 \%$

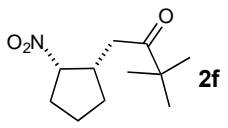

$50 \%, 4: 1,30 \%$

9

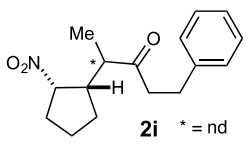

$20 \%, 4: 1:<1,51 \%$

\section{Isolated yield.}

${ }^{\text {b}}$ Determined by $1 \mathrm{H}$ NMR spectroscopy.

'Determined by chiral-phase HPLC using a Chiralpak AD-H column and detection by UV at $280 \mathrm{~nm}$

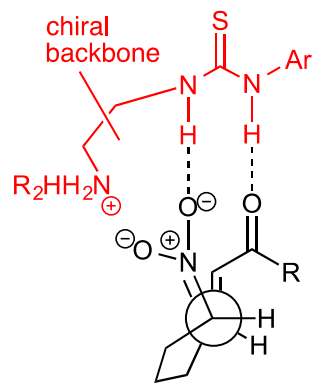

Figure 3 : Proposed transition state showing the preferred co-ordination of the catalyst (red) to the substrate, leading to the cis-configured cyclopentane system.

In conclusion, we have briefly demonstrated that we can extend our catalytic methodology to conjugated ketones in the formation of five-membered ring systems. These constructs are of cis-stereochemistry, and represent an improvement in the selectivity for nitrocyclopentane formation using the bifunctional thiourea catalyst class. This promising data has inspired us to design modified catalyst structures that should be more bespoke for this type of system, and we shall disclose these results in the near future.

\section{Acknowledgment}

We gratefully acknowledge the support of the Ministry of Higher Education and Scientific Research in Iraq for financial support (to W. A), as well as the Chemical Analysis Facility (CAF) at the University of Reading for use of analytical equipment.

\section{References and Notes}

(1) For general reviews see Cobb, A. J. A. In Enantioselective Organocatalyzed Reactions II: Asymmetric C-C Bond Formation Processes; Mahrwald, R., Ed.; Springer: Dordrecht, 2011 and other chapters within both volumes I and II.

(2) (a) Nodes, W. J.; Nutt, D. R.; Chippindale, A. M.; Cobb, A. J. A. J. Am Chem. Soc. 2009, 131, 16016 (b) Rajkumar, S.; Shankland, K.; Brown, G. D.; Cobb, A. J. A. Chem. Sci. 2012, 3, 584 (c) Rajkumar, S.; Shankland, K.; Goodman, J. M.; Cobb, A. J. A. Org. Lett. 2013, 15, 1386. (d) Aitken, L. S.; Arezki, N. R.; Dell'Isola, A.; Cobb, A. J. A. Synthesis 2013, 45, 2627.

(3) Nodes, W. J.; Shankland, K.; Rajkumar, S.; Cobb, A. J. A. Synlett 2010, 3011.

(4) (a) Sato, Y.; Jacobs, W. A. J. Biol. Chem. 1949, 179, 623 (b) Beisler, J. A.; Sato, Y. J. Chem. Soc. C, 1971, 149. (c) Heretsch, P.; Giannis, A. Chapter Four - The Veratrum and Solanum Alkaloids, In: HansJoachim Knölker, Editor(s), The Alkaloids: Chemistry and Biology, Academic Press, 2015, Volume 74, Pages 201-232.

(5) Elworthy, T. R.; Kertesz, D. J.; Kim, W.; Roepel, M. G.; QuattrocchioSetti, L.; Smith, D. B.; Tracy, J. L.; Chow, A.; Li, F.; Brill, E. R.; Lach, L. K.; McGee, D.; Yang, D. S.; Chiou, S.-S. Bioorg. Med. Chem. Lett. 2004, 14, 1655.

(6) See: (a) Okino, T.; Hoashi, Y.; Takemoto, Y. J. Am. Chem. Soc. 2003, 125, 12672 (b) Okino, T.; Hoashi, Y.; Furukawa, T.; Xu, X.; Takemoto, Y. J. Am. Chem. Soc. 2005, 127, 119 (c) Vakulya, B.; Varga, S.; Csámpai, A.; Soós, T. Org. Lett. 2005, 7, 1967. (d) Li, B.-J.; Jiang, L.; Liu, M.; Chen, Y.-C.; Ding, L.-S.; Wu, Y. Synlett 2005, 603. (e) McCooey, S. H.; Connon, S. J. Angew. Chem. Int. Ed. 2005, 44, 6367. (f) Ye, J.; Dixon, D. J.; Hynes, P. S. Chem. Commun. 2005, 4481.

(7) Sohtome, Y.; Tanatani, A.; Hashimoto, Y.; Nagasawa, K. Tetrahedron Lett. 2004, 45, 5589.

(8) Representative procedure : To a solution of (E)-8-nitro-1phenyloct-3-en-2-one (150 mg, $0.6 \mathrm{mmol})$ in acetonitrile $(5 \mathrm{~mL})$ was added catalyst I (60.1 mg, $20 \mathrm{~mol} \%)$ in one portion. The resulting mixture was stirred at room temperature for 7 days, whereupon the solvent was removed under reduced pressure, and the residue purified by column chromatography (diethyl ether:hexane, 1:3) to afford cis-1-(2-nitrocyclopentyl)-3phenylpropan-2-one 2d as a colourless oil (140 mg, 94\%).

(9) Data for 2d : The enantiomeric excess was determined by chiral HPLC analysis at $20{ }^{\circ} \mathrm{C}$ to be $65 \%$ (Chiralpak AD-H $[0.46 \mathrm{~cm} \mathrm{x}$ $\left.25 \mathrm{~cm}]: \mathrm{t}_{1} 32.7 \mathrm{~min}, \mathrm{t}_{2} 39.2 \mathrm{~min}\right) .1 \mathrm{H} \mathrm{NMR}\left(400 \mathrm{MHz}, \mathrm{CDCl}_{3}\right): 1.45$ - $1.48\left(2 \mathrm{H}, \mathrm{m}, \mathrm{CH}_{2} \mathrm{CH}_{2} \mathrm{CHNO}_{2}\right), 1.65-1.68(2 \mathrm{H}, \mathrm{m}$, $\left.\mathrm{C}_{2} \mathrm{CHRCHNO}_{2}\right), 2.10\left(1 \mathrm{H}, \mathrm{m}, \mathrm{CHHCHNO}_{2}\right), 2.34(1 \mathrm{H}, \mathrm{m}$, $\mathrm{CH}_{\underline{\mathrm{H}} \mathrm{CHNO}_{2}}$ ), $2.48(2 \mathrm{H}, \mathrm{m}, \mathrm{cpC} \underline{\mathrm{H}} \mathrm{C}(\mathrm{O})), 2.70\left(1 \mathrm{H}, \mathrm{m}, \mathrm{CHNO}_{2} \mathrm{C} \underline{\mathrm{HR}}\right)$ $3.80\left(2 \mathrm{H}, \mathrm{s}, \mathrm{CH}_{2} \mathrm{Ph}\right), 5.04\left(1 \mathrm{H}, \mathrm{dt}, \mathrm{J} 6.62 .2, \mathrm{CHNO}_{2}\right), 7.17-7.30(5 \mathrm{H}$, $\mathrm{m}, \mathrm{Ar} \underline{\mathrm{H}})$. IR $\left(\mathrm{cm}^{-1}\right): 1260,2973,1714,1544,1458$. HRMS required for $\left(\mathrm{C}_{14} \mathrm{H}_{18} \mathrm{O}_{3} \mathrm{~N}, \mathrm{MH}^{+}\right): 248.1132$; Found 248.1133 . 